\title{
Sea Buckthorn (Hippophae rhamnoides L.) and Quince (Cydonia oblonga L.) Juices and Their By-Products as Ingredients Showing Antimicrobial and Antioxidant Properties for Chewing Candy: Nutraceutical Formulations
}

\author{
Vita Lele, Ema Monstaviciute, Ieva Varinauskaite, Gabriele Peckaityte, Laura Paskeviciute, \\ Monika Plytnikaite, Vitalija Tamosiunaite, Meda Pikunaite, Modestas Ruzauskas, \\ Rolandas Stankevicius, and Elena Bartkiene $\mathbb{D}$
}

Lithuanian University of Health Sciences, Tilzes str. 18, LT-47181 Kaunas, Lithuania

Correspondence should be addressed to Elena Bartkiene; elena.bartkiene@lsmuni.lt

Received 9 April 2018; Revised 29 May 2018; Accepted 7 June 2018; Published 3 July 2018

Academic Editor: Antonio Cilla

Copyright $(2018$ Vita Lele et al. This is an open access article distributed under the Creative Commons Attribution License, which permits unrestricted use, distribution, and reproduction in any medium, provided the original work is properly cited.

Sustainable and environmentally friendly approaches to the production of health foods have become very popular. The concept of this study was to develop chewing candy (CC) - nutraceutical formulations based on sea buckthorn (Hippophae rhamnoides L.) and quince (Cydonia oblonga L.) juice and juice by-products (BuJ, QuJ, BuBP, and QuBP, resp.), as ingredients showing antimicrobial properties against Klebsiella pneumoniae, Salmonella enterica, Pseudomonas aeruginosa, Acinetobacter baumannii, Proteus mirabilis, methicillin-resistant Staphylococcus aureus (MRSA), Enterococcus faecalis, E. faecium, and Bacillus cereus. Two texture-forming agents (agar and gelatin) were tested for CC formulation. BuJ, QuJ, BuBP, and QuBP showed antimicrobial activity against all the pathogens tested, and the largest inhibition zones against Bacillus and Proteus mirabilis were observed for $\mathrm{BuJ}$ and $\mathrm{QuJ}$, respectively. Agar and/or gelatin selection has a significant influence on CC texture $(p=0.0001)$, and interactions of agar and/or gelatin selection $\times$ juice or juice by-products and sea buckthorn or quince $\times$ juice or juice by-products were also significant $(p=0.0001)$. The best acceptability was shown for CC prepared with agar and BuBP (131.7) and with gelatin and QuJ (132.0). The addition of BuJ, QuJ, BuBP, and QuBP increases the antioxidant activity of CC by five times. Finally, not just juice, but also juice by-products, have great potential as desirable antimicrobial ingredients for the food industry.

\section{Introduction}

Many efforts have been made to cope with the agroindustrial waste produced by food manufactories. Nowadays, many by-products (BP) are transformed into useful ingredients, and some of these ingredients have been commercialized and widely used in food, nutraceutical, cosmetic, and other industries [1]. However, vegetables and some fruits yield between $25 \%$ and $30 \%$ of nonedible products, and the BP of fruits and vegetables are made up of skins and seeds of different shapes and sizes that normally have no further usage and are commonly wasted or discarded [2]. Therefore, development of sustainable technologies is still relevant because many BP have until now not been recovered [3]. The very high content of $\mathrm{BP}$ after juice production remains. As juice BP have many biologically active compounds which are healthy for consumers, they can be used for preparation of higher value foods and/or supplements. Higher value food should be attractive for consumers, and juice BP can be incorporated into chewing candy (CC) formulations. In some European and Asian countries, sea buckthorn $(\mathrm{Bu})$ and quince $(\mathrm{Qu})$ fruits are very popular as they have a high content of desirable compounds and show good sensory characteristics [4]. Bu is a good source of mineral acids, vitamins, carbohydrates, amino acids, and natural antioxidants, including phenolics, flavonoids, ascorbic acid, 
TABLE 1: Chewing candy formulas.

\begin{tabular}{|c|c|c|c|c|c|c|c|c|c|c|}
\hline & GC & Sugar, g & Water, $\mathrm{mL}$ & Citric acid, g & A, g & $G, g$ & $\mathrm{Bu} \mathrm{J}, \mathrm{mL}$ & $\mathrm{Bu} \mathrm{BP}, \mathrm{g}$ & $\mathrm{Qu} \mathrm{J}, \mathrm{mL}$ & Qu BP, g \\
\hline \multirow{6}{*}{ A } & $\mathrm{AC}$ & \multirow{10}{*}{30} & 20 & 0.9 & 10 & - & - & - & - & - \\
\hline & $\mathrm{A}+\mathrm{Bu} \mathrm{J}$ & & - & - & & & 20 & - & - & - \\
\hline & $\mathrm{A}+\mathrm{Bu} \mathrm{BP}$ & & 20 & & & & - & 20 & - & - \\
\hline & $\mathrm{A}+\mathrm{Qu} \mathrm{J}$ & & - & & & & - & - & 20 & - \\
\hline & $\mathrm{A}+\mathrm{Qu} \mathrm{BP}$ & & 20 & & & & - & - & - & 20 \\
\hline & GC & & 20 & 0.9 & - & 10 & - & - & - & - \\
\hline \multirow{4}{*}{ G } & $\mathrm{G}+\mathrm{Bu} \mathrm{J}$ & & - & - & & & 20 & - & - & - \\
\hline & $\mathrm{G}+\mathrm{Bu} \mathrm{BP}$ & & 20 & & & & - & 20 & - & - \\
\hline & $\mathrm{G}+\mathrm{Qu} \mathrm{J}$ & & - & & & & - & - & 20 & - \\
\hline & $\mathrm{G}+\mathrm{Qu} \mathrm{BP}$ & & 20 & & & & - & - & - & 20 \\
\hline
\end{tabular}

GC: gummy candies; A: agar; C: control; G: gelatin; J: juice; BP: juice by-products; Bu: sea buckthorn; Qu: quince.

tocopherols, fatty acids, carotenoids, and organic acids, which possess various biological activities [5]. Qu is described as a fruit with high economic and medicinal potential [6]. Also, $\mathrm{Bu}$ and $\mathrm{Qu}$ are good candidates as antimicrobial agents. The main components responsible for the antimicrobial properties of plants are polyphenolic compounds, and it has been shown that the oils from different parts of $\mathrm{Bu}$ inhibit Staphylococcus aureus, Escherichia coli, Bacillus subtilis, and B. coagulans [7]. However, literature about the antimicrobial activity of $\mathrm{Bu}$ and $\mathrm{Qu} \mathrm{BP}$ is scarce. Anyway, BP of $\mathrm{Bu}$ and $\mathrm{Qu}$ juice are not used efficiently enough and taking into account that the botanical dietary supplement segment is anticipated to witness considerable growth over the forecast period on account of the increasing popularity of nutraceuticals with natural ingredients, the development of new products has become very relevant [8]. Nutraceuticals and/or supplements are available in numerous forms including dry, solid or liquid extracts, tablets, capsules, powders, and so on; however, consumers prefer to choose food in traditional form, and incorporation of high value botanical ingredients in CC formulations has become very attractive.

The concept of this study was to develop chewing candy (CC) - nutraceutical formulations based on sea buckthorn (Hippophae rhamnoides L.) and quince (Cydonia oblonga L.) juice and juice by-products (BuJ, QuJ, BuBP, and QuBP, resp.), as ingredients showing antimicrobial properties against Klebsiella pneumoniae, Salmonella enterica, Pseudomonas aeruginosa, Acinetobacter baumannii, Proteus mirabilis, methicillin-resistant Staphylococcus aureus (MRSA), Enterococcus faecalis, E. faecium, and Bacillus cereus. Two texture-forming agents (agar and gelatin) were tested for CC formulation.

\section{Materials and Methods}

2.1. Materials Used for Chewing Candy Preparation. Bu (Hippophae rhamnoides L., variety “Щербинка”) and Qu (Cydonia oblonga L., variety "Rondo") were purchased from local farms (from Klaipeda and Alytus districts, resp., Lithuania). $\mathrm{Bu}$ and $\mathrm{Qu}$ juice ( $\mathrm{BuJ}$ and $\mathrm{QuJ}$, resp.) prepared from fresh fruits and juice by-products (BuBP and QuBP, resp.), the dry part after juice preparation, were prepared at laboratory scale by using a "KENWOOD JE850" juicer at the Lithuanian University of Health Sciences (Kaunas,
Lithuania). Juice and by-products were used fresh without pasteurisation and drying, as well as by-products were used with seeds. Agar powder (Gelidium sesquipedale algae, Rapunzel, Germany) was used as a polymer with mucoadhesive properties for CC formation. Gelatin (Klingai, Kaunas, Lithuania) was also tested. Sugar was obtained from Nordic Sugar (Kedainiai, Lithuania), xylitol from Natur Hurtig (Nuremberg, Germany), and citric acid from Sanitex (Kaunas, Lithuania).

\subsection{Evaluation of the Acidity Parameters of Sea Buckthorn and} Quince Products. The $\mathrm{pH}$ values of $\mathrm{BuJ}, \mathrm{QuJ}, \mathrm{BuBP}$, and QuBP were measured and recorded using a $\mathrm{pH}$ electrode (PP-15; Sartorius, Goettingen, Germany). The total titratable acidity (TTA) was determined for a $10 \mathrm{~g}$ sample of BP and/or juice homogenized with $90 \mathrm{~mL}$ of distilled water and expressed as millilitres of $0.1 \mathrm{~mol} \cdot \mathrm{L}^{-1} \cdot \mathrm{NaOH}$ required to achieve a $\mathrm{pH}$ of 8.2 .

2.3. Chewing Candy Formulas. The control CC formula consisted of sugar $(30 \mathrm{~g})$, water $(20 \mathrm{~g})$, citric acid $(0.90 \mathrm{~g})$, agar $(10.0 \mathrm{~g})$, and/or gelatin (10.0 g) (Table 1). Chewing candies were prepared by addition to the main formula of $\mathrm{Bu}$ (Rhamnus, family Rhamnaceae) and/or Qu (C. oblonga, family Rosaceae) juice or BP. It should be mentioned that candies with juice and/or BP were prepared without the addition of citric acid. For preparation of candies with agar, firstly, agar powder was soaked in water for $30 \mathrm{~min}$ and then melted by heating for $5 \mathrm{~min}$; then, sugar and/or xylitol was added and dissolved under boiling conditions. The mixture obtained was further heated to $103 \pm 2^{\circ} \mathrm{C}$ under stirring. Citric acid was incorporated into the control CC mass at the end of the process. For preparation of CC with gelatin, firstly, gelatin powder was soaked in water for $30 \mathrm{~min}$, and then melted at $80 \pm 2^{\circ} \mathrm{C}$; then, sugar and/or xylitol and citric acid were added and dissolved. After mixing, the mass obtained (both that prepared with agar and prepared with gelatin) was poured into a mould, and CC were dried at $22-24^{\circ} \mathrm{C}$ for $24 \mathrm{~h}$ to get a gel-hard form.

\subsection{Evaluation of Antimicrobial Activity of Sea Buckthorn and} Quince Juices and Their By-Products. An agar well diffusion assay was used for testing the antimicrobial activity of BuJ, 
QuJ, BuBP, and QuBP. For this purpose, a 0.5 McFarland unit density suspension of each pathogenic bacteria strain was inoculated onto the surface of cooled Mueller-Hinton agar (Oxoid, UK) using sterile cotton swabs. Wells $6 \mathrm{~mm}$ in diameter were punched in the agar and filled separately with $\mathrm{BuJ}, \mathrm{QuJ}, \mathrm{BuBP}$, and/or QuBP. Juice and juice production by-products were used fresh without pasteurisation and drying. The antimicrobial activity against tested bacteria was determined by measuring the diameter of inhibition zones $(\mathrm{mm})$. The experiments were repeated three times, and the average of inhibition zones was calculated.

\subsection{Determination of Total Phenolic Compound (TPC)} Content, Antioxidant Activity, and Colour Characteristics of Chewing Candies. The TPC in juice and BP samples was determined by a spectrophotometric method, as reported elsewhere [9]. The absorbance of samples was measured at $765 \mathrm{~nm}$ using a J.P. Selecta S.A. V-1100D spectrophotometer (Barcelona, Spain). Antioxidant activity of the samples was evaluated according to the method reported by Zhu et al. [10]. Colour characteristics were evaluated using a CIE $L^{*} a^{*} b^{*}$ system (Croma Meter CR-400, Konica Minolta, Japan) [11].

2.6. Evaluation of Chewing Candy Texture. The hardness of CC was evaluated by using a TA.XT2 texture analyser (Stable Micro Systems Ltd., Godalming, UK) (compression force $0.5 \mathrm{~N}$, test speed $0.5 \mathrm{~mm} \cdot \mathrm{s}^{-1}$, posttest speed $2 \mathrm{~mm} \cdot \mathrm{s}^{-1}$, distance $6 \mathrm{~mm}$ ).

2.7. Evaluation of Overall Acceptability of Chewing Candies. Overall acceptability of CC was evaluated according to ISO method 8586-1 [12] for preliminary sensory acceptability, using a $150 \mathrm{~mm}$ hedonic line scale ranging from 150 (extremely like) to 0 (extremely dislike).

2.8. Statistical Analysis. The results were expressed as the mean value of at least three measurements \pm standard deviation. In order to evaluate the effects of the different formula components on CC quality parameters, data were analysed by analysis of variance (IBM SPSS Statistics, ver. 22). Results were recognized as statistically significant at $p \leq 0.05$.

\section{Results and Discussion}

3.1. Antimicrobial Activity of Sea Buckthorn and Quince Juices and Their By-Products. The antimicrobial activity of BuJ, $\mathrm{QuJ}, \mathrm{BuBP}$, and QuBP is shown in Table 2. BuJ, QuJ, BuBP, and $\mathrm{QuBP}$ showed antimicrobial activity against all the pathogenic bacteria tested; comparing the antimicrobial activity of juice, the largest inhibition zones for $\mathrm{BuJ}$ and $\mathrm{QuJ}$ were observed against B. cereus $(29.0 \pm 0.5$ and $30.0 \pm$ $0.7 \mathrm{~mm}$, resp.) and Proteus mirabilis $(25.0 \pm 0.6$ and $26.0 \pm$ $0.4 \mathrm{~mm}$, resp.). In most cases, BuBP and QuBP showed weaker antimicrobial activity than the juice (on average, BuBP inhibition zones were 0 to $7 \mathrm{~mm}$ smaller, and QuBP zones were 0 to $5 \mathrm{~mm}$ smaller). The antimicrobial activity of
BuBP ranged from $8.0 \pm 0.4$ to $25.0 \pm 0.5 \mathrm{~mm}$ (for K. pneumoniae and B. cereus inhibition, resp.) and of QuBP from $8.0 \pm 0.4$ to $26.0 \pm 0.5 \mathrm{~mm}$ (for S. enterica and B. cereus inhibition, resp.). The inhibition zones for juice and BP were found to be the same for $S$. enterica (11.0 and $8.0 \mathrm{~mm}$ for $\mathrm{Bu}$ and $\mathrm{Qu}$ products, resp.). Antibiotic resistance is one of the biggest threats to global health, food security, and development today [13], and natural botanical sources showing antimicrobial activity against antibiotic-resistant pathogens can be very important. It was published that $n$-hexane and chloroform extracts of Bu berries and $\mathrm{n}$-hexane extract of $\mathrm{Bu}$ leaves show significant $(p<0.05)$ antibacterial activity comparable with vancomycin, and it was concluded that extracts of $\mathrm{Bu}$ berries and leaves have antibacterial activity against MRSA [14]. According to Fattouch et al. [15], polyphenolic extract of $\mathrm{Qu}$ peel shows antimicrobial activity against Gram-positive (S. aureus) and Gram-negative bacteria (E. coli and P. aeruginosa) and yeast (Candida albicans). The MIC of ethanolic extract of Qu peel ranges between 0.1 and $5.0 \mathrm{mg} \cdot$ polyphenol. $\mathrm{mL}^{-1}$ [16]. Both $\mathrm{Bu}$ and $\mathrm{Qu}$ have a high phenolic compound content, and recent studies have shown that phenolic compounds mostly modulate the composition of gut microbial communities through the inhibition of pathogenic bacteria and stimulation of beneficial bacteria; in the latter, phenolic compounds may exert a prebiotic function and increase the population of beneficial bacteria, including probiotics, suggesting a mutual relationship between phenolic compounds and probiotics [17-19]. The main components responsible for the antimicrobial properties of plants are polyphenolic compounds; they exhibit anti-inflammatory activity in vitro and in vivo, and their mechanism of action is the inhibition of enzymes (phospholipase oxygenase), that is, by binding with hydrosulphide groups and inactivating bacterial proteins [20]. According to our results, not just the juice, but also $\mathrm{BuBP}$ and $\mathrm{QuBP}$ have great potential as antimicrobial ingredients for the food industry.

3.2. Acidity Parameters and Colour Coordinates of Sea Buckthorn and Quince Juices and Their By-Products. Acidity parameters and colour coordinates of $\mathrm{BuJ}, \mathrm{QuJ}$, $\mathrm{BuBP}$, and QuBP are shown in Figures 1(a) and 1(b). Comparing juice and $\mathrm{BP}$, lower $\mathrm{pH}$ values were obtained for the juice (compared to $\mathrm{BP}, \mathrm{BuJ} \mathrm{pH}$ was lower by $24.0 \%$ and $\mathrm{QuJ} \mathrm{pH}$ was lower by 10.4\%) (Figure 1(a)). Opposite to $\mathrm{pH}$ values, $\mathrm{BuJ}$ TTA was two times lower than that of $\mathrm{BP}$; however, QuJ TTA was 1.9 times higher than that of BP. BuBP and QuBP showed higher lightness $\left(L^{*}\right)$ values than juice; $L^{*}$ coordinates ranged from $29.82 \pm 0.96$ to $35.84 \pm$ 1.27 for $\mathrm{BuJ}$ and $\mathrm{BuBP}$, respectively, and from $36.23 \pm 1.63$ to $48.53 \pm 1.08$ for $\mathrm{QuJ}$ and QuBP, respectively (Figure $1(\mathrm{~b})$ ). Different tendencies of $\mathrm{Bu}$ and $\mathrm{Qu}$ redness $\left(a^{*}\right)$ were observed when comparing juice and BP. Coordinates of $a^{*}$ for $\mathrm{BuJ}$ were $49.9 \%$ lower than those for $\mathrm{BP}$; however, $a^{*}$ coordinates for $\mathrm{QuJ}$ were $30.7 \%$ higher than those for BP. In all cases, higher yellowness $\left(b^{*}\right)$ coordinates were found for BP than for juice (BuBP $b^{*}$ coordinates $155.2 \%$ higher, QuBP 56.2\% higher). 
TABLE 2: Antimicrobial activity of buckthorn and quince juices and their 363 by-products.

\begin{tabular}{|c|c|c|c|c|}
\hline \multirow{3}{*}{ Microorganisms } & \multicolumn{2}{|c|}{$\mathrm{J}$} & \multicolumn{2}{|c|}{$\mathrm{BP}$} \\
\hline & $\mathrm{Bu}$ & $\mathrm{Qu}$ & $\mathrm{Bu}$ & $\mathrm{Qu}$ \\
\hline & \multicolumn{4}{|c|}{ Inhibition zones, $\mathrm{mm}$} \\
\hline Klebsiella pneumoniae & $14.0 \pm 0.3^{\mathrm{d}}$ & $13.0 \pm 0.3^{\mathrm{c}}$ & $8.0 \pm 0.4^{\mathrm{a}}$ & $10.0 \pm 0.3^{\mathrm{b}}$ \\
\hline Salmonella enterica & $11.0 \pm 0.2^{\mathrm{b}}$ & $8.0 \pm 0.2^{\mathrm{a}}$ & $11.0 \pm 0.3^{\mathrm{b}}$ & $8.0 \pm 0.4^{\mathrm{a}}$ \\
\hline Pseudomonas aeruginosa & $23.0 \pm 0.4^{\mathrm{b}}$ & $23.0 \pm 0.3^{\mathrm{b}}$ & $20.0 \pm 0.2^{\mathrm{a}}$ & $20.0 \pm 0.2^{\mathrm{a}}$ \\
\hline Acinetobacter baumannii & $20.0 \pm 0.5^{c}$ & $22.0 \pm 0.3^{\mathrm{d}}$ & $16.0 \pm 0.1^{\mathrm{a}}$ & $19.0 \pm 0.3^{b}$ \\
\hline Proteus mirabilis & $25.0 \pm 0.6^{c}$ & $26.0 \pm 0.4^{\mathrm{c}, \mathrm{d}}$ & $20.0 \pm 0.2^{\mathrm{a}}$ & $23.0 \pm 0.4^{\mathrm{b}}$ \\
\hline MRSA & $22.0 \pm 0.3^{c}$ & $22.0 \pm 0.2^{\mathrm{c}}$ & $17.0 \pm 0.2^{\mathrm{a}}$ & $18.0 \pm 0.2^{\mathrm{b}}$ \\
\hline Enterococcus faecalis & $25.0 \pm 0.4^{\mathrm{c}}$ & $23.0 \pm 0.3^{\mathrm{b}}$ & $18.0 \pm 0.3^{\mathrm{a}}$ & $18.0 \pm 0.2^{\mathrm{a}}$ \\
\hline Enterococcus faecium & $20.0 \pm 0.3^{\mathrm{b}}$ & $22.0 \pm 0.3^{c}$ & $18.0 \pm 0.2^{\mathrm{a}}$ & $22.0 \pm 0.4^{\mathrm{c}}$ \\
\hline Bacillus cereus & $29.0 \pm 0.5^{c}$ & $30.0 \pm 0.7^{\mathrm{d}}$ & $25.0 \pm 0.5^{\mathrm{a}}$ & $26.0 \pm 0.5^{\mathrm{a}, \mathrm{b}}$ \\
\hline
\end{tabular}

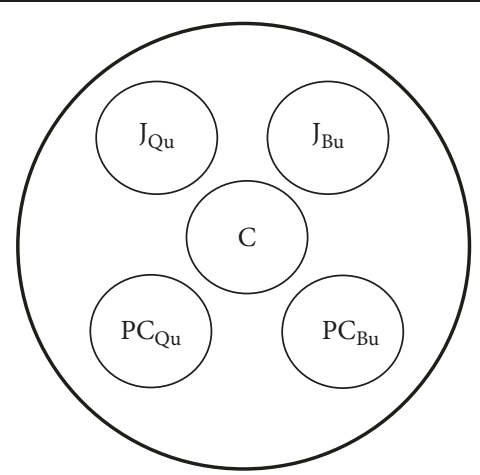

Experimental design

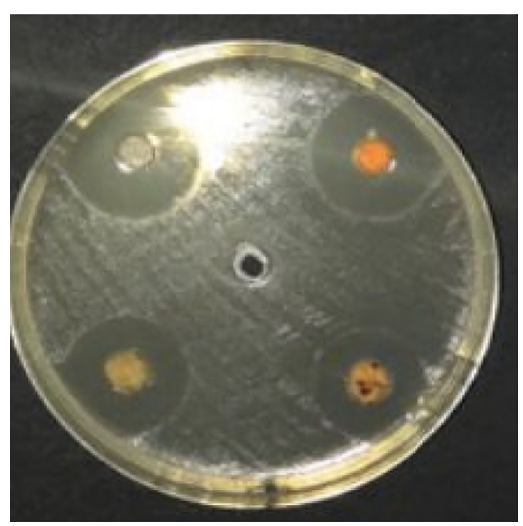

Proteus mirabilis

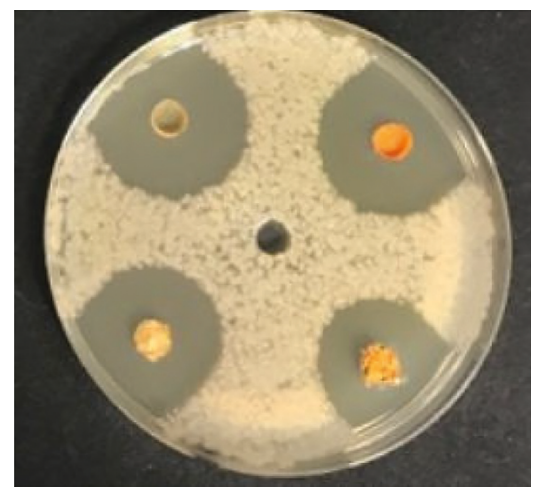

Bacillus cereus

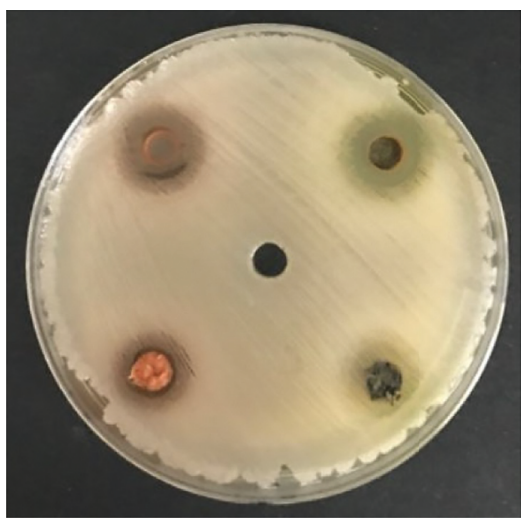

Klebsiella pneumoniae

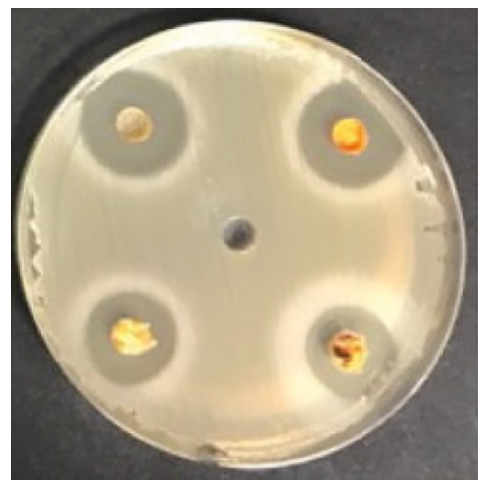

MRSA

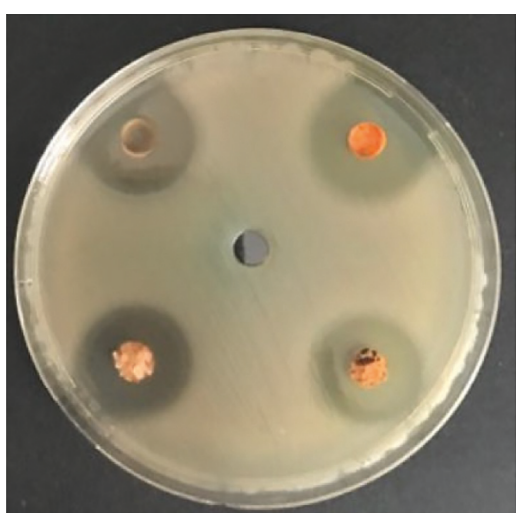

Pseudomonas aeruginosa

J: juice; BP: juice by-products; Bu: sea buckthorn; Qu: quince; C: control; MRSA: methicillin-resistant Staphylococcus aureus. Data expressed as means $(n=3) \pm$ standard deviation (SD). ${ }^{\text {a-d }}$ Mean values with different letters are significantly different when $p \leq 0.05$.

The main components of Bu identified are ascorbic acid, carotenoids, and various phenolics, including proanthocyanidins, gallic acid, ursolic acid, caffeic acid, coumaric acid, ferulic acid, catechin and epicatechin derivatives, quercetin, kaempferol, and isorhamnetin glycoside derivatives [21]. However, colour is influenced by carotenoids, and the main carotenoids of $\mathrm{Bu}$ are $\alpha$-, $\beta$-, and $\delta$-carotene and lycopene [22]. It was published that the edible parts of $\mathrm{Qu}$ can have $16.8 \mathrm{mg} \cdot 100 \cdot \mathrm{g}^{-1}$ ascorbic acid; this is the main compound which influences the sour taste of these fruits [6].

3.3. Texture, Colour Characteristics, and Overall Acceptability of Chewing Candies. CC texture, colour characteristics, and overall acceptability are shown in Table 3 . Comparing the CC group prepared with agar (A), the hardest texture was obtained for the CC prepared with BuBP (hardness of $\mathrm{A}+\mathrm{BuBP}$ samples was $1.00 \pm 0.01 \mathrm{~mJ})$. Compared with control CC (AC), CC prepared with the addition of juice and/or BP were harder in all cases (from 35\% to $400 \%$ for CC prepared with $\mathrm{BuJ}$ and $\mathrm{BuBP}$, resp.). Comparing the $\mathrm{CC}$ group prepared with gelatin $(\mathrm{G})$, the hardest texture was obtained for the $\mathrm{CC}$ with $\mathrm{BuJ}$ (hardness of $\mathrm{G}+\mathrm{BuJ}$ samples was $3.13 \pm 0.12 \mathrm{~mJ}$ ); in contrast, CC prepared with the addition of BuBP had the softest texture (37.1\% softer). In all cases, CC prepared with juice were harder than the candies prepared with the addition of BP. Selection of A and/or G 


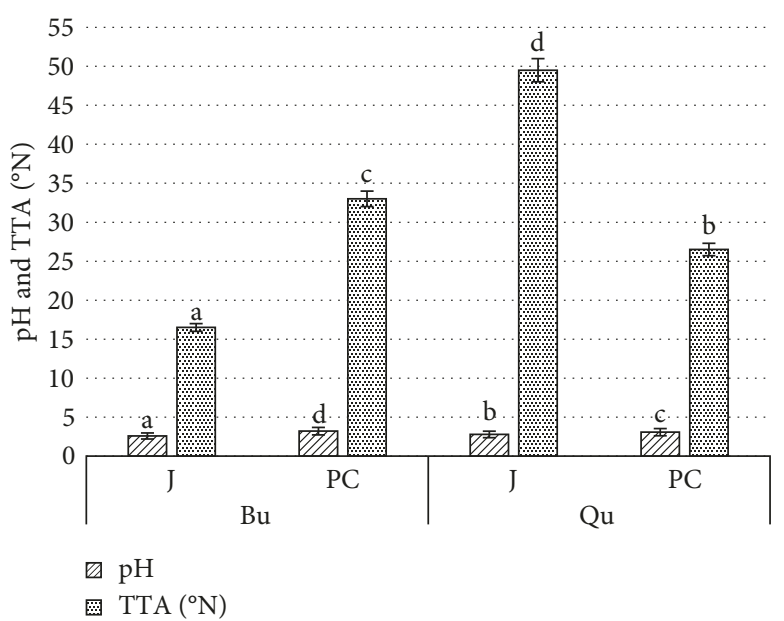

(a)

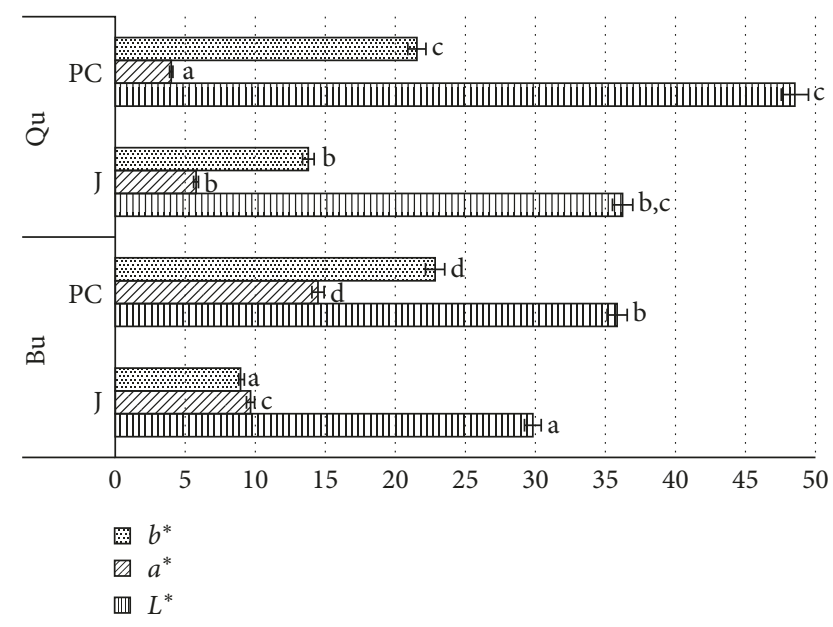

(b)

Figure 1: Acidity parameters (a) and colour coordinates (b) of sea buckthorn ( $\mathrm{Bu})$ and quince $(\mathrm{Qu})$ juice (J) and juice by-products (PC) (BuJ, QuJ, BuBP, and QuBP, resp.).

had a significant influence on CC texture $(p=0.0001)$, and interactions of $\mathrm{A}$ and/or $\mathrm{G}$ selection $\times$ juice or $\mathrm{BP}$ and $\mathrm{Bu}$ or $\mathrm{Qu} \times$ juice or BP were also significant $(p=0.0001)$.

In all cases, higher lightness $\left(L^{*}\right)$ coordinates were obtained for CC prepared with A (on average $48.3 \%$ higher compared to CC prepared with G). Most of the factors analysed had a significant influence on CC $L^{*}$ coordinates (except A and/or G selection). Comparing control CC prepared with $A$ and $G$, no significant changes were found for redness $\left(a^{*}\right)$ coordinates; however, comparing $a^{*}$ coordinates of CC prepared with the addition of $\mathrm{Bu}$ and $\mathrm{Qu}$ products (juice and/or BP), a different influence of A and/or G selection on $a^{*}$ coordinates was established. Samples prepared with BuBP and A had $60.5 \%$ higher redness than samples prepared with $\mathrm{G}$; in contrast, CC prepared with $\mathrm{G}$ and $\mathrm{QuJ}$ and $\mathrm{BP}$ had $143.6 \%$ and $35.4 \%$ higher redness, respectively, than samples prepared with agar. Comparing yellowness $\left(b^{*}\right)$, CC prepared with $\mathrm{G}$ had $b^{*}$ coordinates $44.6 \%$ lower than those of the control CC. However, $b^{*}$ coordinates of CC were more influenced by the addition of $\mathrm{Bu}$ and $\mathrm{Qu}$ products (juice and/or $\mathrm{BP}$ ), and the highest $b^{*}$ was obtained for the CC prepared with $\mathrm{G}$ and $\mathrm{BuJ}(27.44 \pm 2.15)$. Bu or $\mathrm{Qu}$ selection $(p=0.0001)$ and juice or BP selection $(p=0.0001)$ had a significant influence on CC $a^{*}$ and $b^{*}$ coordinates, and interactions of $\mathrm{A}$ and/or $\mathrm{G} \times \mathrm{Bu}$ or $\mathrm{Qu}, \mathrm{A}$ and/or $\mathrm{G} \times$ juice or $\mathrm{BP}$, and $\mathrm{Bu}$ or $\mathrm{Qu} \times$ juice or $\mathrm{BP}$ were also significant.

No significant differences were obtained for overall acceptability between the control CC samples prepared with $A$ and G; however, most of the CC prepared with the addition of $\mathrm{Bu}$ and $\mathrm{Qu}$ products (juice and/or $\mathrm{BP}$ ) were more acceptable than controls. The best acceptability was obtained for CC prepared with A and BuBP $(131.7 \pm 10.7)$ and CC prepared with $\mathrm{G}$ and $\mathrm{QuJ}(132.0 \pm 7.8)$. CC prepared with $\mathrm{A}$ and $\mathrm{BuBP}$ was also hardest; however, no correlation was found between hardness and overall acceptability of CC. A significant influence of the interaction of analysed factors $\mathrm{A}$ and/or G selection $\times$ juice or BP on overall acceptability was established $(p=0.001)$.
Pressing of juice produces large amounts of pomace, which are currently discarded as waste or utilized rather inefficiently; therefore, considerable amounts of nutrients are lost annually [23]. Finally, development of new products in which the whole BP can be used is very important; it leads to reduced production costs because extracts should not be prepared. Further, in our experiment, the best acceptability was found for $\mathrm{CC}$ formulas improved by changing saccharose to xylitol $(1: 1)$. In comparing the parameters of CC samples with saccharose and xylitol, no significant changes were observed, except in overall acceptability which was significantly higher for the CC with xylitol.

\subsection{Total Phenolic Compound Content and Antioxidant Ac-} tivity of Chewing Candies. The TPC content and antioxidant activity of the CC are presented in Table 4. Comparing CC groups prepared with A and G, in all cases, control CC samples had a lower TPC content (in the CC group prepared with A, from $132.7 \%$ to $312.5 \%$ lower, for CC with BuBP and QuJ, resp.; in the group prepared with $\mathrm{G}$, from $44.5 \%$ to $160.9 \%$ lower, for $\mathrm{CC}$ with $\mathrm{QuJ}$ and $\mathrm{BuBP}$, resp.) than $\mathrm{CC}$ prepared with the addition of $\mathrm{Bu}$ and $\mathrm{Qu}$ products (juice and/or $\mathrm{BP}$ ). Also, comparing CC control groups, a $45.0 \%$ higher TPC content was obtained for the CC group prepared with G; however, no significant differences in antioxidant activity of control CC groups were established. In all cases (in both CC groups prepared with A and with G), stronger antioxidant activity was established for the CC prepared with $\mathrm{Qu}$ and Bu products (juice and/or BP): in the CC group prepared with A, from $130.7 \%$ to $563.7 \%$ higher (in $\mathrm{CC}$ prepared with the addition of $\mathrm{BuJ}$ and $\mathrm{QuBP}$, resp.), and in the group prepared with $\mathrm{G}$, from $95.2 \%$ to $325.8 \%$ higher (in $\mathrm{CC}$ prepared with the addition of $\mathrm{BuJ}$ and $\mathrm{QuBP}$, resp.). A significant influence of the parameters analysed (A or G selection; $\mathrm{Bu}$ or Qu; juice or BP) on TPC content in CC $(p=0.0001)$ and their antioxidant activity $(p=0.0004, p=0.0001$ and $p=0.0001$, resp.) was observed. Interactions of $\mathrm{Bu}$ or $\mathrm{Qu} \times$ juice or $\mathrm{BP}$ were also significant for the antioxidant properties of $\mathrm{CC}$ 
TABLE 3: Hardness, colour coordinates, and overall acceptability of gummy candies.

\begin{tabular}{|c|c|c|c|c|c|c|}
\hline \multirow{2}{*}{ GC } & & \multirow{2}{*}{ Texture, mJ } & \multicolumn{3}{|c|}{ Colour coordinates } & \multirow{2}{*}{ Overall acceptability } \\
\hline & & & $L^{*}$ & $a^{*}$ & $b^{*}$ & \\
\hline \multirow{6}{*}{ A } & $\mathrm{AC}$ & $0.20 \pm 0.01^{\mathrm{a}}$ & $46.05 \pm 4.32^{\mathrm{d}}$ & $1.57 \pm 0.28^{c}$ & $13.63 \pm 1.44^{\mathrm{e}}$ & $85.3 \pm 4.2^{\mathrm{a}}$ \\
\hline & $\mathrm{A}+\mathrm{Bu} \mathrm{J}$ & $0.27 \pm 0.05^{\mathrm{a}}$ & $28.42 \pm 4.55^{\mathrm{a}}$ & $3.72 \pm 0.21^{\mathrm{e}}$ & $13.30 \pm 2.18^{\mathrm{e}}$ & $114.7 \pm 9.5^{\mathrm{d}}$ \\
\hline & $\mathrm{A}+\mathrm{Bu} \mathrm{BP}$ & $1.00 \pm 0.01^{\mathrm{d}}$ & $27.27 \pm 1.49^{\mathrm{a}}$ & $2.38 \pm 0.23^{\mathrm{d}}$ & $13.20 \pm 1.35^{\mathrm{e}}$ & $131.7 \pm 10.7^{\mathrm{f}}$ \\
\hline & $\mathrm{A}+\mathrm{Qu} \mathrm{J}$ & $0.43 \pm 0.06^{\mathrm{b}}$ & $31.39 \pm 1.98^{\mathrm{b}}$ & $0.94 \pm 0.16^{\mathrm{a}}$ & $10.88 \pm 1.05^{\mathrm{c}}$ & $107.0 \pm 12.1^{\mathrm{d}}$ \\
\hline & $\mathrm{A}+\mathrm{Qu} \mathrm{BP}$ & $0.80 \pm 0.01^{\mathrm{c}}$ & $27.40 \pm 0.81^{\mathrm{a}}$ & $0.96 \pm 0.06^{\mathrm{a}}$ & $10.08 \pm 0.39^{b}$ & $124.0 \pm 10.4^{\mathrm{e}}$ \\
\hline & $\mathrm{A}+\mathrm{Bu} \mathrm{BP}+\mathrm{Xy}$ & $1.00 \pm 0.01^{\mathrm{d}}$ & $28.30 \pm 1.23^{\mathrm{a}}$ & $2.34 \pm 0.17^{\mathrm{d}}$ & $13.04 \pm 1.14^{\mathrm{e}}$ & $147.7 \pm 2.3^{\mathrm{g}}$ \\
\hline \multirow{6}{*}{ G } & GC & $2.07 \pm 0.15^{\mathrm{e}}$ & $48.45 \pm 1.46^{\mathrm{e}}$ & $1.56 \pm 0.32^{\mathrm{c}}$ & $7.55 \pm 1.52^{\mathrm{a}}$ & $90.4 \pm 5.1^{\mathrm{b}}$ \\
\hline & $\mathrm{G}+\mathrm{BuJ}$ & $3.13 \pm 0.12^{\mathrm{h}}$ & $49.44 \pm 0.16^{\mathrm{e}}$ & $3.93 \pm 0.39^{\mathrm{e}}$ & $27.44 \pm 2.15^{\mathrm{f}}$ & $108.7 \pm 22.9^{\mathrm{d}}$ \\
\hline & $\mathrm{G}+\mathrm{Bu} \mathrm{BP}$ & $1.97 \pm 0.25^{\mathrm{e}}$ & $34.60 \pm 0.88^{c}$ & $0.94 \pm 0.11^{\mathrm{a}}$ & $12.49 \pm 0.21^{\mathrm{d}}$ & $99.3 \pm 17.6^{\mathrm{b}, \mathrm{c}}$ \\
\hline & $\mathrm{G}+\mathrm{Qu} \mathrm{J}$ & $2.70 \pm 0.11^{\mathrm{g}}$ & $58.81 \pm 4.53^{\mathrm{f}}$ & $2.29 \pm 0.17^{\mathrm{d}}$ & $12.74 \pm 1.04^{\mathrm{d}}$ & $132.0 \pm 7.8^{\mathrm{f}}$ \\
\hline & $\mathrm{G}+\mathrm{Qu} \mathrm{BP}$ & $2.53 \pm 0.01^{f}$ & $46.60 \pm 0.96^{\mathrm{d}}$ & $1.30 \pm 0.14^{\mathrm{b}}$ & $7.54 \pm 0.32^{\mathrm{a}}$ & $96.3 \pm 6.7^{\mathrm{b}}$ \\
\hline & $\mathrm{G}+\mathrm{Qu} \mathrm{J}+\mathrm{Xy}$ & $2.67 \pm 0.09^{f}$ & $58.62 \pm 3.21^{\mathrm{f}}$ & $2.26 \pm 0.12^{\mathrm{d}}$ & $12.68 \pm 0.93^{\mathrm{d}}$ & $142.0 \pm 3.6^{\mathrm{g}}$ \\
\hline
\end{tabular}

Influence of different texture-forming agents (A or $\mathrm{G}$ ), different plants (Bu or Qu), and J or BP C of plants on gummy candy parameters Source Dependent variable Texture A or $G$ Colour coordinates $\mathrm{Bu}$ or $\mathrm{Qu}$ Overall acceptability Texture

Overall acceptability
Texture

J or C

Colour coordinates

Overall acceptability Texture

A or $\mathrm{G} \times \mathrm{Bu}$ or $\mathrm{Qu}$

Colour coordinates

A or $\mathrm{G} \times \mathrm{J}$ or $\mathrm{C}$

Overall acceptability Texture

Colour coordinates

$\mathrm{Bu}$ or $\mathrm{Qu} \times \mathrm{J}$ or $\mathrm{C}$

Overall acceptability

Texture

Overall acceptability
Texture

A or $\mathrm{G} \times \mathrm{Bu}$ or $\mathrm{Qu} \times \mathrm{J}$ or $\mathrm{C} \quad$ Colour coordinates

Overall acceptability

$\begin{array}{lr} & \text { Mean } \\ & \\ L^{*} & 1433 \\ a^{*} & \\ b^{*} & \\ & 19 \\ & \end{array}$

Mean square

\begin{tabular}{|c|c|}
\hline$F$ & $p$ \\
\hline 2501.853 & 0.0001 \\
\hline 252.122 & 0.0001 \\
\hline 0.837 & 0.371 \\
\hline 0.708 & 0.410 \\
\hline 1.217 & 0.283 \\
\hline 0.287 & 0.598 \\
\hline 44.519 & 0.0001 \\
\hline 216.690 & 0.0001 \\
\hline 125.212 & 0.0001 \\
\hline 0.129 & 0.723 \\
\hline 1.871 & 0.186 \\
\hline 74.884 & 0.0001 \\
\hline 202.689 & 0.0001 \\
\hline 91.852 & 0.0001 \\
\hline 0.430 & 0.519 \\
\hline 1.022 & 0.324 \\
\hline 25.806 & 0.0001 \\
\hline 61.524 & 0.0001 \\
\hline 44.868 & 0.0001 \\
\hline 3.362 & 0.082 \\
\hline 208.900 & 0.0001 \\
\hline 36.177 & 0.0001 \\
\hline 51.055 & 0.0001 \\
\hline 88.665 & 0.0001 \\
\hline 15.297 & 0.001 \\
\hline 14.041 & 0.001 \\
\hline 0.195 & 0.663 \\
\hline 81.462 & 0.0001 \\
\hline 19.715 & 0.0001 \\
\hline 1.914 & 0.182 \\
\hline 64.475 & 0.0001 \\
\hline 1.034 & 0.321 \\
\hline 2.956 & 0.101 \\
\hline 19.550 & 0.0001 \\
\hline 1.914 & 0.182 \\
\hline
\end{tabular}

GC: gummy candies; A: agar; C: control; G: gelatin; J: juice; BP: juice by-products; Bu: sea buckthorn; Qu: quince; Xy: xylitol. $L^{*}:$ lightness; $a^{*}:$ redness (- $a^{*}$ : greenness); $b^{*}$ : yellowness $\left(-b^{*}\right.$ : blueness). Data are represented as means $(n=3) \pm \mathrm{SD} .{ }^{\mathrm{a}-\mathrm{g}}$ Mean values with different letters are significantly different when $p \leq 0.05$.

$(p=0.0001)$, and interactions of $\mathrm{A}$ or $\mathrm{G}$ selection $\times$ juice or $\mathrm{BP}$ and $\mathrm{Bu}$ or $\mathrm{Qu} \times$ juice $\mathrm{BP}$ selection were significant for TPC content in CC. The main phytochemicals present in $\mathrm{Qu}$ (quercetin, 5-O-caffeoylquinic acid, rutin, $\beta$-carotene, lycopene, $\beta$-cryptoxanthin, lutein, plus zeaxanthin) have received attention due to their high antioxidant potential and capability of preventing and treating pathologies [24]. Total antioxidant activity in $\mathrm{Bu}$ is significantly associated with total phenolics, isorhamnetin-3-rutinoside, and isorhamnetin-3-glucoside [25]. Therefore, strong antioxidant activity of Bu has been reported by several authors [26]. Finally, BuJ, QuJ, BuBP, and QuBP increased the TPC content and antioxidant activity of the CC, and 
TABLE 4: Total phenolic compounds (TPC) content and antioxidant activity of gummy candies.

\begin{tabular}{|c|c|c|c|}
\hline & & TPC content, RE mg.100.g ${ }^{-1}$ & Antioxidant activity, $\%$ \\
\hline \multirow{6}{*}{ A } & $\mathrm{AC}$ & $47.1 \pm 3.1^{\mathrm{a}}$ & $12.4 \pm 1.9^{\mathrm{a}}$ \\
\hline & $\mathrm{A}+\mathrm{Bu} J$ & $153.5 \pm 6.4^{\mathrm{f}}$ & $28.6 \pm 1.7^{\mathrm{c}}$ \\
\hline & $A+B u B P$ & $194.3 \pm 7.2^{\mathrm{i}}$ & $35.2 \pm 2.8^{\mathrm{f}}$ \\
\hline & $\mathrm{A}+\mathrm{Qu} \mathrm{J}$ & $109.6 \pm 4.3^{\mathrm{d}}$ & $41.8 \pm 3.4^{\mathrm{g}}$ \\
\hline & $A+Q u B P$ & $162.1 \pm 4.7^{\mathrm{g}}$ & $57.5 \pm 3.1^{\mathrm{i}}$ \\
\hline & $\mathrm{A}+\mathrm{Bu} \mathrm{BP}+\mathrm{Xy}$ & $186.1 \pm 4.5^{\mathrm{i}}$ & $36.4 \pm 1.8^{\mathrm{f}}$ \\
\hline \multirow{6}{*}{ G } & GC & $68.3 \pm 3.4^{\mathrm{b}}$ & $12.4 \pm 0.7^{\mathrm{a}}$ \\
\hline & $\mathrm{G}+\mathrm{Bu} \mathrm{J}$ & $149.4 \pm 5.6^{\mathrm{e}}$ & $24.2 \pm 1.6^{\mathrm{b}}$ \\
\hline & $\mathrm{G}+\mathrm{Bu} \mathrm{BP}$ & $178.2 \pm 7.0^{\mathrm{h}}$ & $31.6 \pm 2.3^{\mathrm{d}}$ \\
\hline & $\mathrm{G}+\mathrm{Qu} \mathrm{J}$ & $98.7 \pm 4.3^{c}$ & $37.3 \pm 2.9^{f}$ \\
\hline & $\mathrm{G}+\mathrm{Qu} \mathrm{BP}$ & $143.5 \pm 6.2^{\mathrm{e}}$ & $52.8 \pm 3.4^{\mathrm{h}}$ \\
\hline & $\mathrm{G}+\mathrm{Qu} \mathrm{J}+\mathrm{Xy}$ & $100.3 \pm 3.9^{c}$ & $34.1 \pm 1.6^{\mathrm{e}}$ \\
\hline
\end{tabular}

Influence of different texture-forming agents (A or $\mathrm{G})$, different plants (Bu or $\mathrm{Qu}$ ), and J or BP of plants on gummy candy parameters

\begin{tabular}{|c|c|c|c|c|}
\hline Source & Dependent variable & Mean square & $F$ & $p$ \\
\hline \multirow{2}{*}{ A or $G$} & TPC content & 45.679 & 1.565 & 0.225 \\
\hline & Antioxidant activity & 65.473 & 10.259 & 0.004 \\
\hline \multirow{2}{*}{$\mathrm{Bu}$ or $\mathrm{Qu}$} & TPC content & 9780.844 & 335.144 & 0.0001 \\
\hline & Antioxidant activity & 1827.015 & 286.276 & 0.0001 \\
\hline \multirow{2}{*}{$\mathrm{J}$ or $\mathrm{C}$} & TPC content & 10445.854 & 357.931 & 0.0001 \\
\hline & Antioxidant activity & 766.140 & 120.047 & 0.0001 \\
\hline \multirow{2}{*}{$\mathrm{A}$ or $\mathrm{G} \times \mathrm{Bu}$ or $\mathrm{Qu}$} & TPC content & 32.434 & 1.111 & 0.304 \\
\hline & Antioxidant activity & 0.540 & 0.085 & 0.774 \\
\hline \multirow{2}{*}{ A or $\mathrm{G} \times \mathrm{J}$ or $\mathrm{C}$} & TPC content & 145.534 & 4.987 & 0.037 \\
\hline & Antioxidant activity & 0.135 & 0.021 & 0.886 \\
\hline \multirow{2}{*}{$\mathrm{Bu}$ or $\mathrm{Qu} \times \mathrm{J}$ or $\mathrm{C}$} & TPC content & 287.734 & 9.859 & 0.005 \\
\hline & Antioxidant activity & 110.940 & 17.383 & 0.0001 \\
\hline \multirow{2}{*}{$\mathrm{A}$ or $\mathrm{G} \times \mathrm{Bu}$ or $\mathrm{Qu} \times \mathrm{J}$ or $\mathrm{C}$} & TPC content & 6.934 & 0.238 & 0.631 \\
\hline & Antioxidant activity & 0.375 & 0.059 & 0.811 \\
\hline
\end{tabular}

GC: gummy candies; A: agar; C: control; G: gelatin; J: juice; BP: juice by-products; Bu: sea buckthorn; Qu: quince; TPC: total phenolic compounds; RE: rutin equivalents. $L^{*}$ : lightness; $a^{*}$ : redness $\left(-a^{*}\right.$ : greenness); $b^{*}$ : yellowness $\left(-b^{*}\right.$ : blueness). Data are represented as means $(n=3) \pm \mathrm{SD} .{ }^{\mathrm{a}-\mathrm{i}}$ Mean values with different letters are significantly different when $p \leq 0.05$.

incorporation of these ingredients into the main formula leads to the preparation of products with better functionality.

\section{Conclusions}

$\mathrm{BuJ}, \mathrm{QuJ}, \mathrm{BuBP}$, and QuBP showed antimicrobial activity against all the pathogenic bacteria tested; according to the results obtained, not just the juice, but also BP have great potential as desirable antimicrobial ingredients for the food industry. In all cases, BuJ, QuJ, BuBP, and QuBP increase the TPC content and antioxidant activity of the CC. However, A and/or $\mathrm{G}$ selection $(p=0.0001)$ and interactions of $\mathrm{A}$ and/or $\mathrm{G}$ selection $\times$ juice or $\mathrm{BP}$ and $\mathrm{Bu}$ or $\mathrm{Qu} \times$ juice or $\mathrm{BP}$ $(p=0.0001)$ have a significant influence on CC texture. Combination of $\mathrm{A}$ and $\mathrm{BuBP}$ and of $\mathrm{G}$ and $\mathrm{QuJ}$ leads to the preparation of products with a high degree of overall acceptability containing desirable antimicrobials.

\section{Data Availability}

The data used to support the findings of this study are available from the corresponding author upon request.

\section{Conflicts of Interest}

The authors declare that there are no conflicts of interest regarding the publication of this paper.

\section{References}

[1] T. Varzakas, G. Zakynthinos, and F. Verpoort, "Plant food residues as a source of nutraceuticals and functional foods," Foods, vol. 5, no. 4, p. 88, 2016.

[2] C. M. Ajila, S. G. Bhat, and U. J. S. Prasada Rao, "Valuable components of raw and ripe peels from two Indian mango varieties," Food Chemistry, vol. 102, no. 4, pp. 1006-1011, 2007.

[3] P. F. Carvalho, "Mining industry and sustainable development: time for change," Food and Energy Security, vol. 6, no. 2, pp. 61-77, 2017.

[4] A. Voicu, G. Campeanu, M. Bibicu, and M. Catana, "Achievement of a fortifying product based on apples, quinces and sea buckthorn," Notulae Botanicae Horti Agrobotanici Cluj-Napoca, vol. 37, no. 1, pp. 224-228, 2009.

[5] A. Zielińska and I. Nowak, "Abundance of active ingredients in sea buckthorn oil," Lipids in Health and Disease, vol. 16, no. 1, p. 95, 2017. 
[6] R. Sharma, V. K. Joshi, and J. C. Rana, "Nutritional composition and processed products of quince (Cydonia oblonga Mill)," Indian Journal of Natural Products and Resources, vol. 2, pp. 354-357, 2011.

[7] X. F. Yue, X. Shang, Z. J. Zhang, and Y. N. Zhang, "Phytochemical composition and antibacterial activity of the essential oils from different parts of sea buckthorn (Hippophae rhamnoides L.)," Journal of Food and Drug Analysis, vol. 25, no. 2, pp. 327-332, 2017.

[8] J. Sherry, Nutraceuticals Market Size worth $\$ 578.23$ Billion by 2025 CAGR: 8.8\%, Grand View Research, Inc., San Francisco, CA, USA, 2018.

[9] M. Vaher, K. Matso, T. Levandi, K. Helmja, and M. Kaljurand, "Phenolic compounds and the antioxidant activity of the bran, flour and whole grain of different wheat varieties," Procedia Chemistry, vol. 2, no. 1, pp. 76-82, 2010.

[10] Y. Zhu, M. Teng, and X. Li, "Crystallization and preliminary crystallographic studies of the NAD+-dependent deacetylase HST1 from Saccharomyces cerevisiae," Acta Crystallographica, Section F, Structural Biology Crystal Communications, vol. 67, no. 12, pp. 1579-1581, 2011.

[11] G. R. McGuire, "Reporting of objective color measurements," Feature, vol. 27, no. 12, pp. 1254-1255, 1992.

[12] ISO, Sensory Analysis: General Guidance for Selection, Training and Monitoring of Assessors. Part 1: Selected Assessors, Method 8586-1, ISO, Geneva, Switzerland, 2000.

[13] WHO (World Health Organization), Antibiotic Resistance: Fact Sheets 1-5, WHO, Geneva, Switzerland, 2018.

[14] M. I. Qadir, K. Abbas, A. Younus, and R. S. Shaikh, "Antibacterial activity of sea buckthorn (Hippophae rhamnoides L.) against methicillin resistant Staphylococcus aureus (MRSA)," Pakistan Journal of Pharmaceutical Sciences, vol. 29, no. 5, pp. 1711-1713, 2016.

[15] S. Fattouch, P. Caboni, V. Coroneo et al., "Antimicrobial activity of Tunisian quince (Cydonia oblonga Miller) pulp and peel polyphenolic extracts," Journal of Agricultural and Food Chemistry, vol. 55, no. 3, pp. 963-969, 2007.

[16] G. Mandalari, P. C. Nueno, K. Tuohy et al., "In vitro evaluation of the prebiotic activity of a pectic oligosaccharide-rich extract enzymatically derived from bergamot peel," Applied Microbiology and Biotechnology, vol. 73, no. 5, pp. 1173-1179, 2007.

[17] T. Ozdal, D. A. Sela, J. Xiao, D. Boyacioglu, F. Chen, and E. Capanoglu, "The reciprocal interactions between polyphenols and gut micro-biota and effects on bioaccessibility," Nutrients, vol. 8, no. 2, p. 78, 2016.

[18] D. G. Llano, I. Gil-Sanchez, A. Eteban-Fernandez et al., "Reciprocal beneficial effects between wine polyphenols and probiotics: an exploratory study," European Food Research and Technology, vol. 243, no. 3, pp. 531-538, 2017.

[19] M. Succi, P. Tremonte, G. Pannella et al., "Survival of commercial probiotic strains in dark chocolate with high cocoa and phenols content during the storage and in a static in vitro digestion model," Journal of Functional Foods, vol. 35, pp. 60-67, 2017.

[20] M. Cioch, P. Satora, M. Skotniczny, D. Semik-Szczurak, and T. Tarko, "Characterisation of antimicrobial properties of extracts of selected medicinal plants," Polish Journal of Microbiology, vol. 66, no. 4, pp. 463-472, 2017.

[21] J. S. Kim, "Investigation of phenolic, flavonoid, and vitamin contents in different parts of Korean ginseng (Panax ginseng C.A. Meyer)," Preventive Nutrition and Food Science, vol. 21, no. 3, pp. 263-270, 2016.
[22] N. P. Bekker and A. I. Glushenkova, "Components of certain species of the Elaeagnaceae family," Chemistry of Natural Compounds, vol. 37, no. 2, pp. 97-116, 2001.

[23] C. M. Galanakis, "Recovery of high added-value components from food wastes: conventional, emerging technologies and commercialized applications," Trends in Food Science \& Technology, vol. 26, no. 2, pp. 68-87, 2012.

[24] E. J. Yun, S. Yu, and K. H. Kim, "Current knowledge on agarolytic enzymes and the industrial potential of agarderived sugars," Applied Microbiology and Biotechnology, vol. 101, no. 14, pp. 5581-5589, 2017.

[25] R. Guo, X. Guo, T. Li, X. Fu, and R. H. Liu, "Comparative assessment of phytochemical profiles, antioxidant and antiproliferative activities of sea buckthorn (Hippophae rhamnoides L.) berries," Food Chemistry, vol. 221, pp. 997-1003, 2017.

[26] E. Šne, R. Galoburda, and D. Seglina, "Sea buckthorn vegetative parts-a good source of bioactive compounds," Journal of Latvian Academy of Sciences, vol. 67, no. 2, pp. 101-108, 2013. 


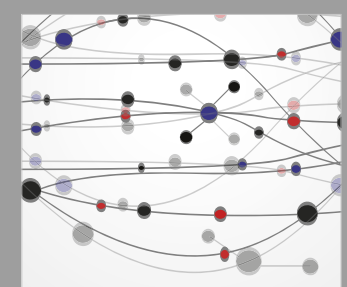

The Scientific World Journal
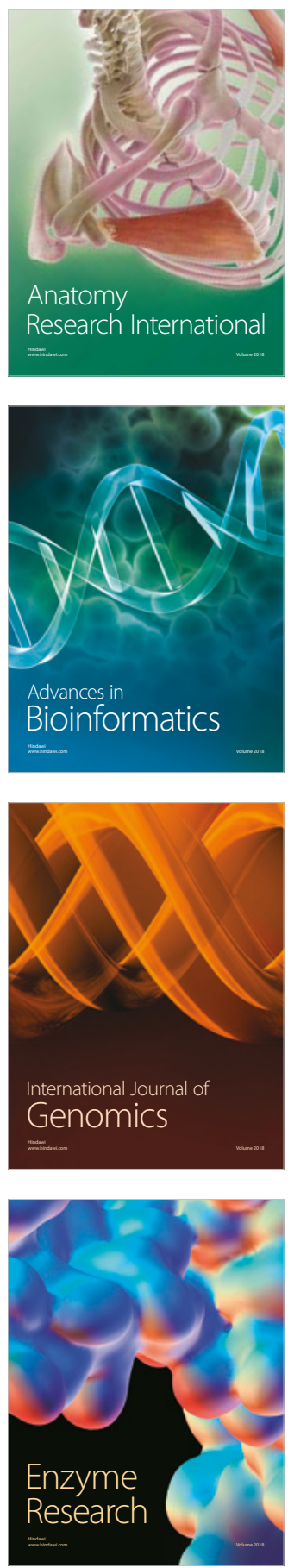
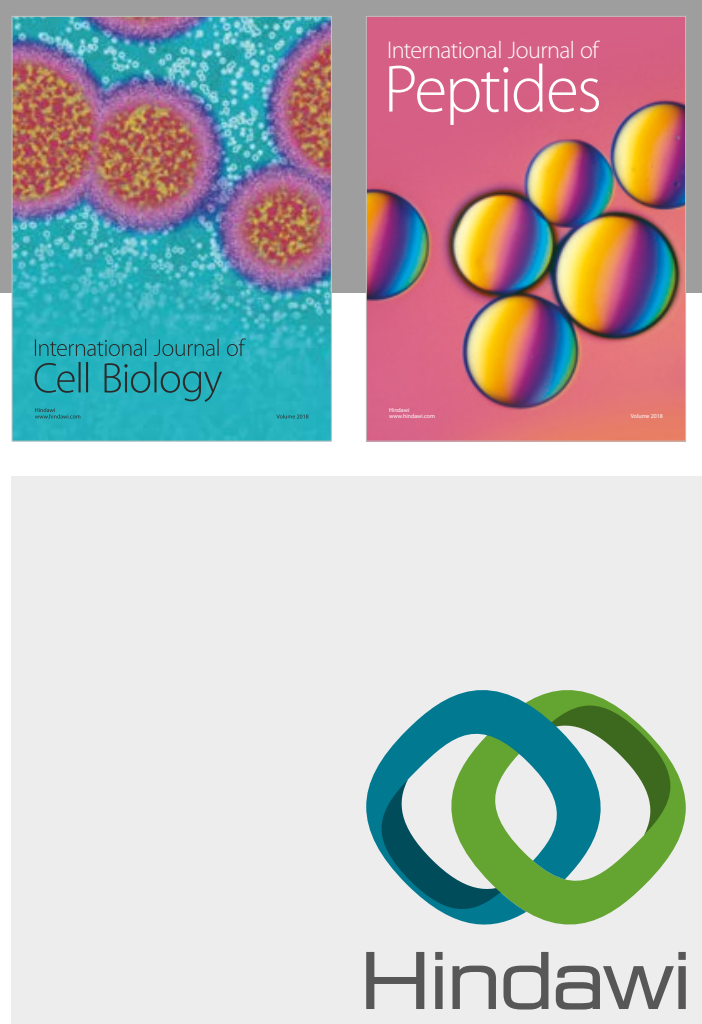

Submit your manuscripts at

www.hindawi.com
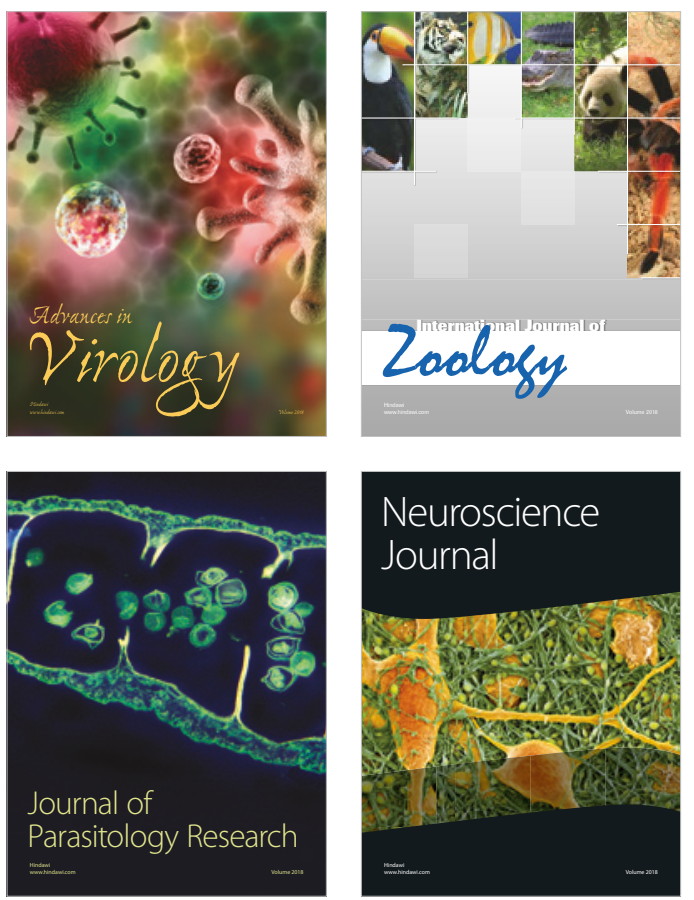
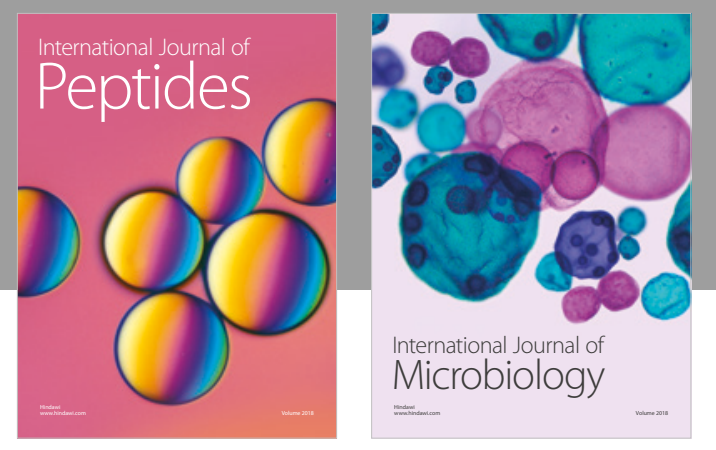

nternational Journal of Microbiology
Journal of
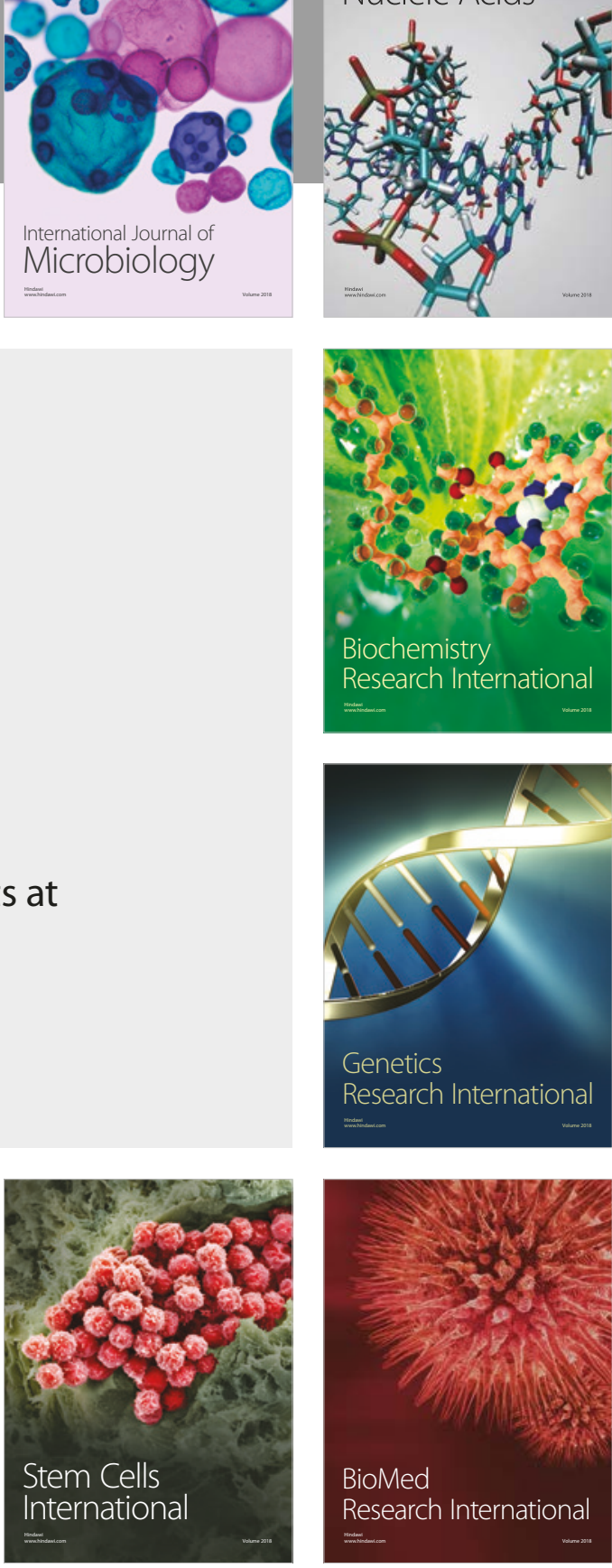
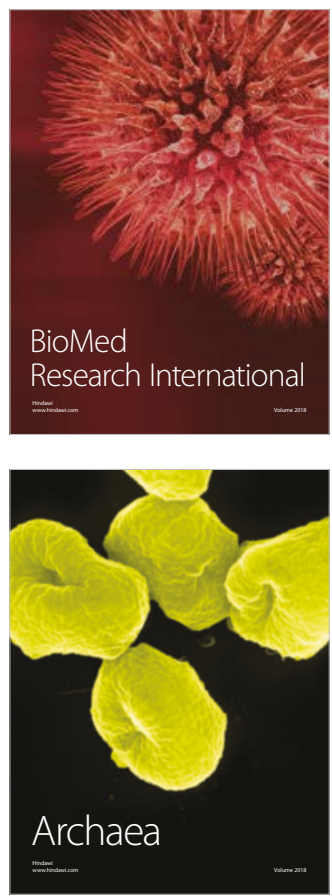